\title{
Sex hormone-binding globulin as a marker for hyperinsulinemia and/or insulin resistance in obese children
}

\author{
Felix Gascón, Miguel Valle, Rosario Martos ${ }^{1}$, Francisco $\mathrm{J} \mathrm{Ruz}^{2}$, Rafael Ríos, Pedro Montilla ${ }^{3}$ and Ramón Cañete ${ }^{4}$ \\ Department of Clinical Laboratory, Valle de los Pedroches Hospital, Pozoblanco, Córdoba, Spain, Basic Health Zones of ${ }^{1}$ Palma del Río and ${ }^{2}$ Hinojosa \\ del Duque, Córdoba, Spain, ${ }^{3}$ Department of Biochemistry, University of Córdoba, Spain and ${ }^{4}$ Department of Pediatric Endocrinology, Reina Sofía \\ Hospital, Córdoba, Spain \\ (Correspondence should be addressed to F Gascón, Department of Clinical Laboratory, Valle de los Pedroches Hospital, 14400 Pozoblanco, Córdoba, \\ Spain; Email: labpozo@mx3.redestb.es)
}

\begin{abstract}
Objective: A relationship between hyperinsulinemia and decreased serum sex hormone-binding globulin (SHBG) has been described in adults. We evaluated the usefulness of SHBG as an index of hyperinsulinemia and/or insulin resistance in obese children (aged 6-9 years) of both sexes and its possible influence on the androgenic status.

Design: We carried out a cross-sectional study of cases and controls. We studied 61 obese children (22 males, 39 females) with body mass index (BMI) superior to the $90^{\text {th }}$ percentile and a control group of age- and sex-matched non-obese children. We measured serum glucose, insulin, TSH, free thyroxine, $17 \beta$-estradiol, testosterone and SHBG. Also, we correlated these parameters with anthropometric measures.

Results: The obese group presented significantly elevated levels of insulin $(P=0.001)$ and insulin/ glucose ratio $(P=0.0012)$ compared with the control group. SHBG $(P=0.0001)$ and testosterone $(P=0.0169)$ levels were significantly lower than those in the non-obese group. We did not find any difference in the free androgen index (FAI). Fasting insulin $(r=-0.4512 ; P<0.001)$, BMI $(r=-0.3185 ; P<0.05)$ and testosterone $(r=-0.3705 ; P<0.01)$ were inversely correlated with SHBG concentration. According to multivariate analyses, insulin was the only independent predictor factor for serum SHBG concentration in the obese group ( $\mathrm{r}$ partial $=0.1280 ; P=0.0171$ ).

Conclusions: In summary, at this age there is a strong relationship between insulin and SHBG. The changes in SHBG levels of the obese group did not affect FAI and, therefore, they did not cause changes in the androgenic status. Our data support the role of insulin in the regulation of serum SHBG levels.
\end{abstract}

European Journal of Endocrinology 143 85-89

\section{Introduction}

Sex hormone-binding globulin (SHBG) is a specific steroid-binding plasma glycoprotein, which is mainly synthesized in the liver (1-3). It binds testosterone with high affinity and estrogens with lower affinity. Assuming that only the unbound fraction of testosterone is bioavailable, SHBG functions as a modulator of androgen delivery to tissues.

In the classical paper of Anderson (4), the estrogen/ androgen balance was the main factor in the regulation of SHBG synthesis. Nevertheless, at present, SHBG regulation is considered as multifactorial and other non-steroidal factors seem to have an important role in the circulating levels of this binding protein $(5,6)$.

Now, there is much evidence that insulin may be an important modulator of SHBG concentrations. In vitro, insulin is a potent inhibitor of SHBG production by HepG2 cells (7), and reduces the stimulatory effect of
$17 \beta$-estradiol and thyroxine (8). In vivo, reduced serum SHBG levels have been described in different insulin resistance states with hyperinsulinemia, such as polycystic ovary syndrome (9) or obesity (10). Also, low SHBG concentration is an independent risk factor for non-insulin-dependent diabetes mellitus (NIDDM) (11). Therefore, the relationship between decreased SHBG levels and insulin resistance is present in clinical situations with an increased risk of cardiovascular disease.

Most of the previous studies have been accomplished in adults and little is known of this relationship in children. However, recent studies indicate that features typical of the insulin resistance syndrome with an adverse cardiovascular risk are already present in adolescents $(12,13)$. The current study was designed to investigate whether the SHBG level is a useful index of hyperinsulinemia and/or insulin resistance in obese children (six to nine years old) of both sexes and, if so, whether this association influences the androgen status 
of these children. Also, we seek to correlate these parameters with anthropometric measures.

\section{Subjects and methods Subjects}

We carried out a cross-sectional study of cases and controls. We studied a total of 122 children aged between six and nine years. Sixty-one obese children (22 males, 39 females) with a body mass index (BMI) above the 90th percentile, and the same number of ageand sex-matched non-obese children as a control group (BMI below the 90th percentile) were studied. We used curves of growth for our population (14). All children were in the Tanner stage 1.

The study groups were formed of children from several schools. First, their corresponding pediatricians in the different schools were informed about the realization of the study. Simultaneously, they requested parental authorisation for the participation of their children. All had to give written consent.

After this, we selected the children consecutively among those that accepted participation in the project. The selection of the children was made in the pediatric clinic of health care and each child was included in one or another group according to his BMI, age and sex. Children with primary hyperlipidemia, hypertension, diabetes or hydrocarbonated intolerance were excluded from the study. Any child undergoing pharmacological treatment was also excluded.

\section{Methods}

The blood samples were collected after $12 \mathrm{~h}$ of fast from a vein in the antecubital fossa, without venous occlusion. All collections were made between 0800 and $0900 \mathrm{~h}$. Serum samples were separated from whole blood collected into tubes without anticoagulant. After clotting was complete, the tubes were then centrifuged at $2700 \mathrm{~g}$ for $10 \mathrm{~min}$. Serum was removed and assayed or stored in aliquots at $-45^{\circ} \mathrm{C}$ until the determinations could be performed.

Glucose was determined with a glucose oxidase method in a random access analyzer (Axon, Bayer Diagnostics, Tarrytown, NY, USA). Insulin, thyrotropin (TSH) and free thyroxine $\left(\mathrm{T}_{4}\right)$ were quantified by a microparticle immunoassay in an automatic analyzer (IMx, Abbott Laboratories, Chicago, IL, USA). We used enzyme immunoassay methods for $17 \beta$-estradiol and testosterone (BioChem ImmunoSystems, Bologna, Italy), and for SHBG (Rasim S.A., Liège, Belgium), which were carried out in a microtiter plate analyzer (Labotech, Chemila, Roma, Italy). The coefficients of vatiation were always below 5\% (intra-assay) and 9.5\% (interassay). The free androgen index (FAI), an alternative assessment of free testosterone, was calculated as 100 times the testosterone/SHBG ratio.

\section{Statistical analysis}

Statistical assessment was conducted with Microstat (Ecosoft, Inc.) or GraphPAD InStat (GraphPAD Software) software. The abnormal values (outliers) were excluded by Reed's method. Results were expressed as means \pm S.E.M. and with 95\% confidence interval (CI). The distribution of each variable was tested for departure from gaussian distribution and the equality of variances was controlled by Snedecor's F-test. The comparison between the mean values of the groups was carried out by Student's unpaired $t$-test. Statistical significance was set at $P<0.05$.

Correlation between variables was evaluated by Pearson's correlation coefficient and with regression analysis. The multivariant regression analysis was performed by using the stepwise method. It is important that the statistical procedure includes a check for regression. We must verify that the distribution of residuals is normal and their variance is constant. In this study, the normality of residuals was checked by the $\chi^{2}$ test, and graphic analysis of residuals was carried out to provide information about constancy of variance. Diagnostic measures were used for the detection of problematic observations. An observation was considered an outlier if its residual was >3Sy.x. (standard deviations of residuals). For each variable, potential confounding factors $(0.05<P<0.2)$ were evaluated by analysis of raw and adjusted regression coefficients.

\section{Results}

The patient characteristics (means and s.E.M.) of the studied groups are shown in Table 1 and the measured parameters in Table 2.

The mean values (obese vs control) of insulin (95\% CI $7.20-9.20$ vs $5.45-6.79$ ) and the insulin/glucose ratio (95\% CI $8.35-10.55$ vs $6.34-7.94)$ were significantly greater in the obese group. On the other hand, testosterone $(95 \%$ CI $0.50-0.62$ vs $0.60-0.72)$ and SHBG $(95 \%$ CI $44.2-50.8$ vs $53.8-61.2)$ values were significantly lower in our obese children. The mean $17 \beta$-estradiol and FAI values did not differ between groups, but the FAI/testosterone ratio (not shown) was greater in obese children (2.24 vs $1.94 ; P=0.0131)$.

Table 1 Patient characteristics. Results are expressed as means \pm S.E.M.

\begin{tabular}{lccc}
\hline Parameter & Control & Obese & $\boldsymbol{P}$ \\
\hline Age (years) & $7.7 \pm 0.11$ & $7.7 \pm 0.12$ & $\mathrm{NS}$ \\
Weight $(\mathrm{kg})$ & $27.3 \pm 0.63$ & $37.7 \pm 0.80$ & $<0.0001$ \\
Height $(\mathrm{cm})$ & $127.2 \pm 1.02$ & $129.4 \pm 0.84$ & $\mathrm{NS}$ \\
BMl $\left(\mathrm{kg} / \mathrm{m}^{2}\right)$ & $16.7 \pm 0.18$ & $22.3 \pm 0.27$ & $<0.0001$ \\
Waist/hip ratio & $0.84 \pm 0.005$ & $0.85 \pm 0.006$ & $\mathrm{NS}$ \\
Waist/thigh ratio & $1.46 \pm 0.01$ & $1.43 \pm 0.01$ & $\mathrm{NS}$ \\
\hline
\end{tabular}

NS, not significant. 
Table 2 Measured parameters. Results are expressed as means \pm S.E.M.

\begin{tabular}{lccc}
\hline Parameter & Control & Obese & P \\
\hline Glucose $(\mathrm{mg} / \mathrm{dl})$ & $86.0 \pm 0.71$ & $86.2 \pm 0.73$ & $\mathrm{NS}$ \\
Insulin $(\mathrm{mU} / \mathrm{ml})$ & $6.12 \pm 0.34$ & $8.20 \pm 0.51$ & 0.001 \\
I/G $(\times 100)$ & $7.14 \pm 0.41$ & $9.45 \pm 0.56$ & 0.0012 \\
SHBG $(\mathrm{nmol} / \mathrm{l})$ & $57.5 \pm 1.90$ & $47.5 \pm 1.66$ & 0.0001 \\
$17 \beta$-Estradiol $(\mathrm{nmol} / \mathrm{l})$ & $37.1 \pm 2.06$ & $36.8 \pm 1.37$ & $\mathrm{NS}$ \\
Testosterone $(\mathrm{nmol} / \mathrm{l})$ & $0.66 \pm 0.03$ & $0.56 \pm 0.03$ & 0.0169 \\
FAl & $1.28 \pm 0.10$ & $1.31 \pm 0.12$ & $\mathrm{NS}$ \\
\hline
\end{tabular}

I/G, insulin/glucose ratio; NS, not significant.

Thyroid hormones, which stimulate SHBG secretion, were measured so as to discard any changes in the circulating levels of SHBG as a consequence of the thyroid status, and we found no differences between the thyroid hormone levels of obese and control groups.

Univariant correlation analysis is summarized in Table 3 (obese) and Table 4 (control). In the obese group, SHBG correlated negatively with insulin, insulin/ glucose ratio, BMI, testosterone and FAI. The strongest correlation was between SHBG and the FAI/testosterone ratio. Insulin correlated with the same parameters as SHBG but in a positive manner, and also with the waist/ hip ratio. The correlation coefficients of the insulin/ glucose ratio with these variables were higher than those of insulin. The relationship between SHBG and insulin improved when we used the natural logarithm of insulin ( $r=-0.4725$ vs $r=-0.4512)$ (not shown).

In the control group, the negative correlation of SHBG with insulin, insulin/glucose ratio, BMI, FAI and FAI/testosterone was maintained. The negative correlation with $\mathrm{FAI} /$ testosterone was again the strongest. Insulin and the insulin/glucose ratio were associated significantly and positively with BMI and FAI. Glucose was not correlated with any parameter in the control group. In the obese group (not shown), it was only correlated with insulin $(r=0.3392 ; P<0.01)$.

SHBG, insulin, insulin/glucose ratio or testosterone were not significantly associated with $17 \beta$-estradiol in correlation analysis, in either the obese or the control group.
Because of the intercorrelations between insulin and anthropometric measures, as well as with testosterone, these observations were subjected to multivariate regression analysis to determine which anthropometric and hormonal factors correlated independently with SHBG.

In the obese group, nearly $30 \%$ of the SHBG concentration was explained by the levels of insulin, BMI and testosterone $(R=0.5457 ; P=0.0018)$. However, only insulin was an independent factor of prediction $(\mathrm{r}$ partial $=0.1280 ; P=0.01711$ ); BMI and testosterone lost statistical significance when corrected for insulin.

In the control group, using stepwise multiple regression analysis, insulin and BMI were selected as predictor variables for SHBG $(R=0.4511 ; P=0.00136)$; however, only BMI remained as an independent factor $(\mathrm{r}$ partial $=0.0976 ; P=0.01508$ ).

\section{Discussion}

The control of plasma SHBG concentration, considered initially to be under the direct regulation of sex hormone levels (4), is considered today to be under multifactorial regulation. Indeed, the basal production of SHBG seems to be steroid independent and more related to general metabolic factors and nutritional status $(5,6,15)$. In this way, some hormones such as growth hormone, insulin-like growth factor (IGF)-I and insulin may play a more active role in the regulation of SHBG levels (16-18). Recently, there has been increased interest in the role played by insulin in this multiregulation. It is known that insulin has an inhibitory effect on the synthesis of SHBG. This action may be by a direct mechanism: by using cultured HepG2 cells it has been found that insulin is a potent inhibitor of the basal production of $\operatorname{SHBG}(7,8)$; or by an indirect mechanism: by modifying the IGF-I/IGF binding protein-1 ratio (19) the free fraction of IGF-I is increased, and free IGF-I is also an inhibitor of SHBG synthesis in vitro (20). Anyway, the relationship between insulin and SHBG is a widespread phenomenon in adults $(21-24)$ and is present even in neonates (25). Therefore, evidence suggests that it is a more physiological process than was originally thought (26).

Table 3 Correlation matrix of SHBG with insulin (I), insulin/glucose ratio (I/G), BMI, waist/hip ratio (WHR), waist/thigh ratio (WTR), testosterone (T), FAl and $\mathrm{FAl} /$ testosterone ratio $(\mathrm{FAl} / \mathrm{T})$ in the obese group.

\begin{tabular}{|c|c|c|c|c|c|c|c|}
\hline & SHBG & I & $I / G$ & BMI & WHR & WTR & $\mathbf{T}$ \\
\hline I & $-0.4512^{b}$ & & & & & & \\
\hline $\mathrm{I} / \mathrm{G}$ & $-0.4573^{\mathrm{b}}$ & $0.9904^{a}$ & & & & & \\
\hline BMI & $-0.3185^{d}$ & $0.3764^{c}$ & $0.3846^{c}$ & & & & \\
\hline WHR & -0.2092 & $0.3256^{d}$ & $0.3373^{\mathrm{C}}$ & $0.2963^{d}$ & & & \\
\hline WTR & -0.1486 & 0.2350 & $0.2552^{d}$ & $0.2536^{d}$ & $0.7907^{\mathrm{a}}$ & & \\
\hline $\mathrm{T}$ & $-0.3705^{\mathrm{c}}$ & $0.3582^{C}$ & $0.3809^{c}$ & 0.1306 & -0.0499 & -0.0547 & \\
\hline FAI & $-0.6755^{\mathrm{a}}$ & $0.4421^{b}$ & $0.4664^{b}$ & 0.2159 & 0.1004 & 0.0359 & $0.8550^{a}$ \\
\hline $\mathrm{FAl} / \mathrm{T}$ & $-0.9251^{a}$ & $0.4386^{b}$ & $0.4439^{b}$ & $0.2785^{d}$ & 0.2384 & 0.1406 & $0.3742^{C}$ \\
\hline
\end{tabular}

${ }^{\mathrm{a}} P<0.0001 ;{ }^{\mathrm{b}} P<0.001 ;{ }^{\mathrm{c}} P<0.01 ;{ }^{\mathrm{d}} P<0.05$. 
Table 4 Correlation matrix of SHBG with insulin (I), insulin/glucose ratio (I/G), BMI, waist/hip ratio (WHR), waist/thigh ratio (WTR), testosterone (T), FAl and $\mathrm{FAl} / \mathrm{T}$ ratio in the control group.

\begin{tabular}{|c|c|c|c|c|c|c|c|}
\hline & SHBG & I & $I / G$ & BMI & WHR & WTR & $\mathbf{T}$ \\
\hline I & $-0.3426^{c}$ & & & & & & \\
\hline $\mathrm{I} / \mathrm{G}$ & $-0.3522^{c}$ & $0.9905^{a}$ & & & & & \\
\hline $\mathrm{BMI}$ & $-0.3906^{\mathrm{C}}$ & $0.3318^{C}$ & $0.3190^{d}$ & & & & \\
\hline WHR & -0.0118 & -0.1058 & -0.1247 & 0.0650 & & & \\
\hline WTR & -0.1059 & 0.0860 & 0.0583 & -0.0440 & $0.7149^{a}$ & & \\
\hline $\mathrm{T}$ & -0.0177 & 0.2205 & 0.2004 & 0.1531 & -0.1261 & $-0.3351^{c}$ & \\
\hline FAI & $-0.6606^{\mathrm{a}}$ & $0.3801^{c}$ & $0.3738^{c}$ & $0.3391^{c}$ & 0.0444 & -0.0386 & $0.6756^{\mathrm{a}}$ \\
\hline $\mathrm{FAl} / \mathrm{T}$ & $-0.9477^{a}$ & $0.3450^{c}$ & $0.3473^{C}$ & $0.3685^{c}$ & 0.1543 & 0.2243 & 0.0322 \\
\hline
\end{tabular}

${ }^{\mathrm{a}} P<0.0001 ;{ }^{\mathrm{b}} P<0.001 ;{ }^{\mathrm{c}} P<0.01 ;{ }^{\mathrm{d}} P<0.05$

This association is of special interest because the SHBG level could be a general marker for hyperinsulinemic insulin resistance. This would explain the observation that a low serum SHBG level is a predictor for the development of NIDDM $(11,27,28)$. Hyperinsulinemic insulin resistance is also present in obesity, and low levels of SHBG have been described in obese adults of both sexes $(10,29)$.

In the present study, SHBG was independently and inversely correlated with fasting insulin. Our results confirm that this association, already found in adults, is present in obese children (6 to 9 years old) of both sexes. We studied this age range because it is one of the critical periods in childhood for the development of obesity (30).

We have found a significant increase in insulin in the obese group. Furthermore, the insulin/glucose ratio was also greater than in the control group. These insulin levels, indicative of a hyperinsulinemic state, were correlated with an inverse change in the concentration of SHBG. This relationship is present in both groups, obese and controls, and was sufficiently robust to survive regression analyses. According to the multivariate analyses, insulin is the only independent prediction factor for SHBG levels in obese children. In controls, using a stepwise regression analysis method, insulin and BMI were selected as prediction factors. Therefore, as the relation between SHBG and insulin is present in obese and control groups, we consider that these results support the existence of a physiological relationship.

With respect to the relationship between androgens and anthropometric measures, an association with fat distribution has been described in adults (31). In our study group, we did not find any correlation of testosterone or of SHBG with waist/hip ratio or waist/ thigh ratio. These results support the low usefulness of these indices in this age group (32).

We have also evaluated the effect that the decrease in SHBG found in obese children could have on their androgen levels. In our obese group, the total testosterone levels were below those of the control group. However, we cannot consider this result as real hypogonadism since no alteration in FAI levels was found and, therefore, no change in bioavailable testosterone (33). Thus, at this age, the evaluation of androgenic state in obese children is of little use if evaluated only with total testosterone.

Within the physiological regulations, the relationship between insulin, SHBG and testosterone is complex to explain and as yet, not well established. Insulin has stimulatory effects on androgen secretion (34) and, at the same time, testosterone influences tissue sensitivity to insulin (35). In the present study, considering the regression analysis, we believe that at this age (6 to 9 years old), the relationship between insulin, SHBG and testosterone seems defined, fundamentally, by the action of insulin on the SHBG levels. The decrease in SHBG levels produced by the hyperinsulinism in the obese group underlies the decrease in total testosterone, since SHBG is its main transport. Nevertheless, FAI remained unchanged and, therefore, there is no hypogonadism.

On the other hand, we could think about a relative androgenism if we take into account the FAI/testosterone ratio, which was significantly increased in the obese group. But it is important to indicate that this ratio seems to depend almost $100 \%$ on the SHBG concentration, as shown in our correlation studies. Therefore, the modifications of this index would be secondary to the changes in SHBG levels. Furthermore, in the obese group, the correlation between testosterone and SHBG did not resist the multivariate analyses. These results do not suggest that, in our study group, androgens have a relevant role in the circulating levels of SHBG.

In conclusion, we believe that the relationship between insulin and SHBG could be considered to have a key role in the regulation of the plasma SHBG concentration. In prepubertals, the SHBG decrease in the obese group is consistently related to the increase in insulin with no change in free androgen index. These results suggest that a hyperinsulinemic insulin resistant state may be present in obese children and that SHBG is a good marker for this hyperinsulinism.

\section{Acknowledgements}

We acknowledge the technical assistance of MD Bonilla, A García, C Segura and A Muñoz. This study was supported by grant FIS183/97 from the Fondo de 
Investigaciones Sanitarias de la Seguridad Social, Ministry of Health, Spanish Government.

\section{References}

1 Hammond GL. Molecular properties of corticosteroid binding globulins and the sex-steroid binding proteins. Endocrine Reviews $19901765-79$.

2 Rosner W. The functions of corticosteroid-binding globulin and sex hormone-binding globulin: recent advances. Endocrine Reviews 199017 80-91.

3 Selby C. Sex hormone-binding globulin: origin, function and clinical significance. Annals of Clinical Biochemistry 199027 532-541.

4 Anderson DC. Sex hormone-binding globulin. Clinical Endocrinology 19743 69-96.

5 Schoultz B \& Carlström K. On the regulation of sex hormonebinding globulin: a challenge of an old dogma and outlines of an alternative mechanism. Journal of Steroid Biochemistry and Molecular Biology 198932 327-334.

6 Toscano V, Balducci R, Bianchi P, Guglielmi R, Mangiantini A \& Sciarra F. Steroidal and non-steroidal factors in plasma sex hormone-binding globulin regulation. Journal of Steroid Biochemistry and Molecular Biology 199243 431-437.

7 Loukovaara M, Carson M \& Adlercreutz H. Regulation of production and secretion of sex hormone-binding globulin in HepG2 cell cultures by hormones and growth factors. Journal of Clinical Endocrinology and Metabolism 199580 160-164.

8 Plymate SR, Matej LA, Jones RE \& Friedl K. Inhibition of sex hormone-binding globulin production in the human hepatoma (HepG2) cell line by insulin and prolactin. Journal of Clinical Endocrinology and Metabolism 198867 460-464.

9 Meirow D, Yossepowitch O, Rosler A, Brzezinski A, Schenker JG, Laufer $\mathrm{N}$ et al. Insulin resistant and non-resistant polycystic ovary syndrome represent two clinical and endocrinological subgroups. Human Reproduction $1995101951-1956$.

10 Pasquali R, Casimirri F, Cantobelli S, Melchionda N, MorselliLabate AM, Fabbri $\mathrm{R}$ et al. Effect of obesity and body fat distribution on sex hormones and insulin in men. Metabolism 199140 101-104.

11 Lindstedt G, Lundberg PA, Lapidus L, Lundgren H, Bengtsson C \& Bjorntorp P. Low sex hormone-binding globulin concentration as independent risk factor for development of NIDDM. 12-yr followup of population study of women in Gothenburg, Sweden. Diabetes $199140123-128$.

12 Jiang X, Srinivasan SR, Urbina E \& Berenson GS. Hyperdynamic circulation and cardiovascular risk in children and adolescents. The Bogalusa heart study. Circulation 199591 1101-1106.

13 Bergström E, Hernell O, Persson LA \& Vessby B. Insulin resistance syndrome in adolescents. Metabolism 199645 908-914.

14 Hernández M, Castell J, Narvaiza JL, Rincón JM, Ruiz E, Sánchez E et al. Curvas y tablas de crecimiento. Instituto de investigación sobre crecimiento y desarrollo. Madrid: Garsi, 1988.

15 Pugeat M, Crave JC, Elmidani M, Nicolas MH, Garoscio-Cholet M, Lejeune $\mathrm{H}$ et al. Pathophysiology of sex hormone-binding globulin (SHBG): relation to insulin. Journal of Steroid Biochemistry and Molecular Biology 199140 841-849.

16 Holly JM, Cotterill AM, Jemmotr RC, Shears D, al-Othman S, Chard $\mathrm{T}$ et al. Inter-relations between growth hormone, insulin, insulin-like growth factor-I (IGF-I), IGF-binding protein-1 (IGFBP1) and sex hormone-binding globulin in acromegaly. Clinical Endocrinology 199134 275-280.

17 Ciaccio M, Belgorosky A \& Rivarola MA. Differences in serum insulin-like growth factor I and sex hormone-binding globulin levels between late and early prepuberty in patients with idiopathic and organic growth hormone deficiency. Acta Endocrinologica $1993129419-423$.

18 Oscarsson J, Lindstedt G, Lundberg PA \& Eden S. Continuous subcutaneous infusion of low dose growth hormone decreases serum sex hormone-binding globulin and testosterone concentrations in moderately obese middle-aged men. Clinical Endocrinology 1996 $4423-29$.

19 Ibañez L, Potau N, Georgopoulos N, Prat N, Gussinye M \& Carrascosa A. Growth hormone, insulin-like growth factor-I axis, and insulin secretion in hyperandrogenic adolescents. Fertility and Sterility $1995641113-1119$.

20 Crave JC, Lejeune H, Brebant C. Baret C \& Pugeat M. Differential effects of insulin and insulin-like growth factor $I$ on the production of plasma steroid-binding globulins by human hepatoblastoma-derived (HepG2) cells. Journal of Clinical Endocrinology and Metabolism 199580 1283-1289.

21 Haffner SM. Sex hormone-binding protein, hyperinsulinemia, insulin resistance and non-insulin-dependent diabetes. Hormone Research 199645 233-237.

22 Preziosi P, Barrett-Connor E, Papoz L, Roger M, Saint-Paul M, Nahoul $\mathrm{K}$ et al. Interrelation between plasma sex hormonebinding globulin and plasma insulin in healthy adult women: the Telecom study. Journal of Clinical Endocrinology and Metabolism $199376283-287$.

23 Goodman-Gruen D \& Barret-Connor E. Sex hormone-binding globulin and glucose tolerance in postmenopausal women. The Rancho Bernardo study. Diabetes Care 199720 645-649.

24 Strain G, Zumoff B, Rosner M \& Pi-Sunyer X. The relationship between serum levels of insulin and sex hormone-binding globulin in men: the effect of weight loss. Journal of Clinical Endocrinology and Metabolism 199479 1173-1176.

25 Simmons D. Interrrelation between umbilical cord serum sex hormone, sex hormone-binding globulin, insulin-like growth factor I, and insulin in neonates from normal pregnancies and pregnancies complicated by diabetes. Journal of Clinical Endocrinology and Metabolism $1995802217-2221$.

26 Editorial. Sex hormone-binding globulin: a marker for hyperinsulinemia and/or insulin resistance? Journal of Clinical Endocrinology and Metabolism 199376 273-274.

27 Haffner SM, Valdez RA, Morales PA, Hazuda HP \& Stern MP. Decreased sex hormone-binding globulin predicts non-insulindependent diabetes mellitus in women but not in men. Journal of Clinical Endocrinology and Metabolism 199377 56-60.

28 Haffner SM, Shaten J, Stern MP, Smith GD \& Kuller L. Low levels of sex hormone-binding globulin and testosterone predict the development of non-insulin-dependent diabetes mellitus in men. MRFIT Research Group. Multiple Risk Factor Intervention Trial. American Journal of Epidemiology 1996143 889-897.

29 Bernasconi D, Del-Monte P, Meozzi M, Randazzo M, Marugo A, Badaracco B et al. The impact of obesity on hormonal parameters in hirsute and nonhirsute women. Metabolism $19964572-75$.

30 Dietz WH. Critical periods in childhood for the development of obesity. American Journal of Clinical Nutrition 199459 955-959.

31 Tchernof A, Despres JP, Dupont A, Belanger A, Nadeau A, Prud'homme D et al. Relation of steroid hormones to glucose tolerance and plasma insulin levels in men. Importance of visceral adipose tissue. Diabetes Care 199518 292-299.

32 Caprio S, Hyman LD, McCarthy S, Lange R, Bronson M \& Tamborlane WV. Fat distribution and cardiovascular risk factors in obese adolescent girls: importance of the intra-abdominal fat depot. American Journal of Clinical Nutrition $19966412-17$.

33 Pugeat M. Crave JC. Tourniaire J \& Forest MG. Clinical utility of sex hormone-binding globulin measurement. Hormone Research $199645148-155$.

34 Pasquali R, Casimirri F, De-Iasio R, Mesini P, Boschi S, Chierici R et al. Insulin regulates testosterone and sex hormone-binding globulin concentrations in adult normal weight and obese men. Journal of Clinical Endocrinology and Metabolism $199580654-658$.

35 Ebeling P, Stenman UH, Seppala M \& Koivisto VA. Androgens and insulin resistance in type 1 diabetic men. Clinical Endocrinology $199543601-607$.

Received 29 September 1999

Accepted 15 March 2000 